\title{
1 Satellite data as indicators of tree biomass growth and forest \\ 2 dieback in a Mediterranean holm oak forest.
}

3

4 Abstract.

5

- Context: In the frame of climate change, decreased tree growth and enhanced mortality induced by hot and dry conditions are increasing in many forests around the world, and particularly in Mediterranean forests.

- Aims: Our aim was to estimate tree growth and mortality in a Mediterranean holm oak forest, using remote sensing data from MODIS.

- Methods: We monitored annual increases of aboveground biomass by measuring tree basal area, and we determined tree mortality by counting dead stems. We analyzed the relationships between forest growth and mortality with mean annual values of some MODIS products and meteorological data.

- Results: Mortality and increases of aboveground biomass correlated well with precipitation, September standardized precipitation/evapotranspiration indices (SPEI) and some MODIS products such as NDVI and enhanced vegetation index EVI. Other MODIS products such as gross primary production (GPP) and net photosynthesis, however, showed no clear relationship with tree mortality or measured increases of biomass.

- Conclusion: The MODIS products as proxies of ecosystemic productivity (gross primary productivity, net photosynthesis) were weakly correlated with biomass increase and did not reflect the mortality following the drought of autumn 2011. Nevertheless, NDVI and EVI were efficient indicators of forest productivity and dieback 
27 Keywords: Forest productivity, Mediterranean forest, MODIS, remote sensing, SPEI 28 indices, tree mortality.

31 Introduction.

33 Some forested ecosystems distributed in semi-arid and Mediterranean areas are seasonally exposed to water defficit and may be particularly vulnerable to even slight increases in water deficit, which can reduce tree growth (Barbeta et al. 2013; Ogaya and

36 Peñuelas 2007), lower the condition of crowns (Carnicer et al. 2011; Galiano et al. 37 2012) and increase tree mortality (Allen et al. 2010; Breshears et al. 2005; Peng et al. 38 2011; Williams et al. 2012). Higher air temperatures are projected globally for the 39 coming decades, and higher evapotranspiration rates induced by this increase in 40 temperature and slight decreases in precipitation are expected in many areas, such as the 41 Mediterranean Basin, subjected to seasonal drought (IPCC 2013). General circulation 42 models project an average decrease of $15 \%$ in soil moisture over the next 50 years and a return period of extreme droughts 10 times shorter than in the twentieth century in these

44 Mediterranean regions (Bates et al. 2008). Moreover, strong relationships between 45 deficits in precipitation and subsequent occurrences of hot extremes have been widely 46 observed (Mueller and Seneviratne 2012), and higher frequencies of heat waves 47 coinciding with summer drought, higher evapotranspiration and the subsequent low availability of water are also expected for Mediterranean regions (Fischer and Schar, 49 2010). 
Holm oak (Quercus ilex L.) is a widespread and dominant tree species in sub-

51 humid areas of the Mediterranean Basin. Many tall shrub species with lower growth rates but a higher resistance to drought are associated with holm oak forests (Peñuelas et al. 1998; Ogaya and Peñuelas 2003). Under future drier conditions, higher mortality rates and lower seed production and seedling survival of $Q$. ilex could drive a decrease in the distribution of this dominant species and favor the associated species that are more resistant to a low availability of water (Lloret et al. 2004; Ogaya and Peñuelas 2007).

Monitoring the effects of climate change, particularly drought, on plant growth and mortality in various regions over time requires the use of remote-sensing techniques.

60 Spectral indices from remote-sensing data are widely used to evaluate the structure and 61 functioning of terrestrial ecosystems (Peñuelas and Filella 1998). The normalized difference vegetation index (NDVI), the most widely used remotely sensed index, is mainly used for estimating the fraction of the photosynthetically active radiation (FPAR) absorbed by the canopy (Tucker et al. 1985). The enhanced vegetation index (EVI) was developed to reduce the noise produced by soil background and atmospheric aerosols and to reduce the saturation of the reflectance signal at increasing levels of green biomass, which are commonly associated with the NDVI (Huete et al. 2002). Remote-sensing data can quantify the spatial variation in forest structure and growth (Waring et al. 2006) and stem volume (González Alonso et al. 2006). Both NDVI and EVI can provide good estimates of forest productivity but provide poor estimates of

71 carbon uptake in dense evergreen forests such as those of the Mediterranean region, because these indices are largely insensitive to the short-term changes in $\mathrm{CO}_{2}$ uptake that are caused by water defficit (Garbulsky et al. 2013). 

as tools for the detection and monitoring of biomass increase, forest decline and tree mortality in a typical Mediterranean forest and to assess the use of remote-sensing data from satellites as good indicators of forest productivity and dieback.

Material and methods.

Study site.

83 The study area was a valley (Vall dels Torners) in the Prades Mountains, Catalonia, in 84 northeastern Spain (Fig. 1). This valley is populated by a natural holm oak (Q. ilex L.) 85 forest $\left(41^{\circ} 21^{\prime} \mathrm{N}, 1^{\circ} 2^{\prime} \mathrm{E}\right)$ at an altitude of $750-1050 \mathrm{~m}$ a.s.l. The soil is a Dystric 86 Cambisol over Paleozoic schist, ranging in depth from 35 to $100 \mathrm{~cm}$. The average 87 annual temperature is $11.8^{\circ} \mathrm{C}$, and the average annual rainfall is $659 \mathrm{~mm}$ (data from 1975 to 2012). Summer drought is pronounced and usually lasts for three months. The

89 vegetation is a very dense multi-stem forest (16616 stems $\left.\mathrm{ha}^{-1}\right)$ dominated by $Q$. ilex $\mathrm{L}$.

90 (8633 stems ha $\left.{ }^{-1}\right)$, Phillyrea latifolia L. (3600 stems ha ${ }^{-1}$ ) and Arbutus unedo L. (2200 91 stems $\mathrm{ha}^{-1}$ ), with an abundance of other evergreen species well adapted to dry conditions 92 such as Erica arborea L., Juniperus oxycedrus L., Cistus albidus L. and occasional 93 individuals of deciduous species such as Sorbus torminalis (L.) Crantz and Acer 94 monspessulanum $\mathrm{L}$. This forest has not been perturbed for 65 years, and the maximum 95 height of the dominant species is approximately 6-10 m. Biomass increment and 96 mortality rate of these species were annually measured as described in Barbeta et al. 972013 , from 1999 to 2012.

98 Climate data. 
99 An automated meteorological station installed at the study site has monitored

100 temperature, photosynthetically active radiation, humidity and precipitation since late

101 1998. We estimated temperature and rainfall for years prior to 1998 with data from

102 another meteorological station located at Poblet Monastery, $5.6 \mathrm{~km}$ northeast of our

103 study area and at $510 \mathrm{~m}$ a.s.l. The meteorological data from the Poblet station was

104 collected from late 1974 to July 2002, so we had climatic data for the period from

105 August 1998 to July 2002 from both meteorological stations. We calculated the linear

106 relationships between temperature $\left(R^{2}=0.97\right)$ and rainfall $\left(R^{2}=0.75\right)$ at these two stations

107 for this period to estimate the climatic data at the study site from 1975 . We thus had

108 continuous climate data of the study site from 1975 to 2012.

109

110 Defoliation and mortality.

111 Defoliation and mortality were recorded in 2011. 40 dominant Q. ilex trees, 40

112 dominant $P$. latifolia and 40 dominant $A$. unedo shrubs were randomly selected across

113 the study site in early spring 2011. The intensity of canopy defoliation by herbivores

114 was estimated assessing the remaining petioles of consumed leaves at the end of July

115 2011. Canopy defoliation produced by summer drought conditions was thereafter

116 estimated, in the same trees, assessing the brown color of dead leaves at the end of

117 October 2011(Fig. 2). In both cases, we visually determined the percentage of defoliated

118 or dead leaves in each tree, and later we calculated the mean value for all tree canopies.

119 Eleven categories were established to measure the percentage of defoliation in each tree:

$1200 \%, 10 \%, 20 \%, 30 \%, 40 \%, 50 \%, 60 \%, 70 \%, 80 \%, 90 \%$ and $100 \%$ (mortality), as

121 described in Ogaya and Peñuelas 2004.

122

123 Remote-sensing data. 
124 Remote-sensing data from 2000 to 2012 were obtained from sensors of the Moderate

125 Resolution Imaging Spectroradiometer (MODIS) onboard the Terra and Aqua satellites.

126 The Terra satellite orbits Earth from north to south in the morning, and the Aqua

127 satellite orbits from south to north in the afternoon. We used the normalized difference

128 vegetation index (NDVI) and the enhanced vegetation index (EVI), obtained from the

129 16-day Terra MOD13Q1 and 16-day Aqua MYD13Q1 products, combined in series

130 with 8-day data based on 20 selected $250 \mathrm{~m}$ x $250 \mathrm{~m}$ pixels. We selected the pixels

131 across the distribution of holm oak forest in the valley (Fig. 1). We later calculated the

132 mean values of the 20 selected pixels to estimate the average values of these indices for

133 the entire holm oak forest in the valley.

134 We also used data for gross primary production (GPP) and net photosynthesis

135 (PsnNet) obtained from the 8-day Terra MOD17A2 product, net primary production 136 (NPP) obtained from the annual Terra MOD17A3 product, leaf area index (LAI) and

137 FPAR obtained from the 8-day Aqua MYD15A2 product and the quotient $\left(\mathrm{R}_{858} / \mathrm{R}_{1240}\right)$

138 between the reflectances at $858 \mathrm{~nm}$ (reference) and $1240 \mathrm{~nm}$ (water absorption) from

139 the 8-day Terra MOD09A1 product. All MODIS products were collected from 2000 to

1402010 from a $1 \times 1 \mathrm{~km}$ pixel centered in the study area, except NDVI and EVI data, that

141 were collected in the 20 selected 250 x 250 pixels. Mean annual values of the remotely

142 sensed indices were calculated as annual integrations for each of the growing seasons

143 covered by the NDVI, EVI, GPP, PsnNet, LAI, FPAR and R858/R1240 data, whereas

144 NPP data were directly collected annually.

146 Data analysis.

147 The climate data (1975-2012) allowed us to calculate the standardized precipitation 148 evapotranspiration index (SPEI) (Vicente-Serrano et al. 2010), an index based on the 
149 difference between precipitation and potential evapotranspiration. Evapotranspiration

150 can be very important for determining variability in soil moisture, a key factor in plant-

151 water relations, The inclusion of potential evapotranspiration (PET) in the calculation of

152 the SPEI only affects the index when PET differs from average conditions, for example

153 under scenarios of global change (Vicente-Serrano et al. 2010). We selected September

154 SPEI indices for the comparison of the 2011 summer drought to those of previous years;

155 we used SPEI 3 and SPEI 6 indices (with data from three and six months before

156 September, respectively). We selected September SPEI 6 and December SPEI 12

157 indices for the statistical analyses of the other variables.

158 General linear models were constructed to examine the relationships of tree 159 mortality rates and increases in aboveground biomass with the changes of air

160 temperatures, rainfall and September SPEI 6 and December SPEI 12 indices during the 161 study period (1975-2012). Other general linear models examined the relationships of

162 tree mortality rates and increases in aboveground biomass with mean annual values of

163 NDVI, EVI, GPP, PsnNet and NPP. We have shown linear regressions because they

164 were the relationships that fit better with all the variables studied. All linear models

165 were constructed with the StatView software package (SAS Institute Inc., Cary, North 166 Carolina, USA).

167 Two redundancy analyses (RDAs) were performed to assess the relationships of 168 the physical data on biomass increase and tree mortality. This linear method was chosen 169 after performing a detrended correspondence analysis, which indicated that the length of 170 the gradient was short (Lepš and Šmilauer 2003). The physical variables were used as 171 species (sensu Canoco) and were centered and standardized, because the data differed in 172 scale of measurement. The significance of the first axis was tested using 499 
173 permutations (Lepš and Šmilauer 2003). The biplots show the first two axes and are

174 displayed with CanoDraw. Ordination was performed using Canoco for Windows 4.5.

175

176

177 Results.

178

179 Climate data.

180 Mean annual temperature ranged from $10.7{ }^{\circ} \mathrm{C}$ in 1984 to $13.1{ }^{\circ} \mathrm{C}$ in 2011 , and total

181 annual precipitation ranged from $376 \mathrm{~mm}$ in 2005 to $984 \mathrm{~mm}$ in 1996 (Fig. 3). During 182 this period (1975-2012), mean annual air temperature increased by approximately $1831.5{ }^{\circ} \mathrm{C}\left(R^{2}=0.42, P<0.001\right)$ (Fig. 3). This increase was due to the strong increases of $1842.86{ }^{\circ} \mathrm{C}$ in spring and $2.22{ }^{\circ} \mathrm{C}$ in summer temperatures $\left(R^{2}=0.58, P<0.001\right.$; and $R^{2}=0.40$, $185 P<0.001$, respectively) $(P<0.001)$, while autumn and winter temperatures did not 186 change. Precipitation, however, was quite variable, and annual precipitation decreased 187 only slightly from 1975 to 2011 (Fig. 4). SPEI indices calculated in September were 188 often negative during the later years, with a clear continuous decrease of both SPEI 3 189 and SPEI 6 indices since 1990 (Fig. 5). Both the September SPEI 3 and SPEI 6 indices 190 were lowest in 2011 , when high temperatures coincided with the maximum number of 191 days with no rainfall (133 days with rainfall under $10 \mathrm{~mm}$ ) and when tree mortality 192 occurred.

193

194 Defoliation and mortality.

$195 Q$. ilex was the only species with significant defoliation by herbivores. For instance, 196 there was a heavy infestation bythe caterpillar of the moth Catocala nymphagoga (Esp.) 197 during late spring, that consumed an average $15 \%$ of $Q$. ilex leaves, all young leaves 
198 just flushed in the previous one or two months. By the end of October 2011, just after

199 the long period of hot and dry conditions, Q. ilex trees had lost an average $14 \%$ of their

200 leaves, and few trees were completely defoliated and had dead stems. Q. ilex thus lost,

201 on average, $29 \%$ of their leaves. The other dominant species suffered less defoliation,

202 which was due only to drought: A. unedo shrubs lost approximately $6 \%$ of their leaves,

203 and $P$. latifolia shrubs lost only approximately $1 \%$ of their leaves.

Remote sensing data.

206 NDVI values showed an annual pattern with high values during winter, a decrease 207 during spring, the lowest values during late spring and early summer and a final 208 increase during late summer and autumn (Fig. 6). EVI values had an inverse annual 209 pattern, with maximum values during late spring and early summer and minimum 210 values during winter (Fig. 6).

211 The maximum mean annual NDVI (0.80) occurred in 2003, and the maximum

212 mean annual EVI (0.38) occurred in 2008, when annual precipitation was highest (926 $213 \mathrm{~mm}$ in 2003 and $837 \mathrm{~mm}$ in 2008). The minimum mean annual NDVI and EVI (0.74

214 and 0.33 , respectively) occurred in late autumn and winter 2011 , during the period of 215 high tree mortality. NDVI values remained low during late 2011 and early 2012 and did 216 not exhibit the typical winter recovery. They began to increase slightly during spring 2172012 and reached typical values only at the end of 2012 (Fig. 6). EVI values were low 218 during late 2011 and early 2012, as is usual during winter, but were lower than normal 219 after the drought of autumn 2011 and recovered to typical values during spring 2012 220 (Fig. 6). Increases in BAI and aboveground biomass correlated well with mean annual 221 NDVI and EVI values, the sum of spring and autumn mean temperatures, annual 
precipitation, spring precipitation, the sum of spring and summer precipitation, and

223 September SPEI 6 and SPEI 12 indices (Table 1).

GPP and PsnNet values had a different annual pattern, with low values during

winter, maximum values during spring, a decrease during summer, another increase in autumn (albeit with lower values than in spring) and a final decrease during late autumn and winter (Fig. 7). GPP and PsnNet values in 2011 were higher than the mean values of the period 2000-2010, except during the severe drought in September and October, but GPP and PsnNet values completely recovered in late autumn (Fig. 7).

The canonical axis (RDA axis 1) explained $46.4 \%$ of the total variance in the analysis of biomass increase, and the overall model was significant ( $P=0.01)$ (Fig. 8).

232 The canonical axis (RDA axis 1) explained $25.1 \%$ of the total variance in the analysis of 233 tree mortality, and the overall model was significant $(P=0.01)$ (Fig. 9). As shown in 234 Figs. 8 and 9, a group of variables (NDVI, EVI, LAI, FPAR, $\mathrm{R}_{850} / \mathrm{R}_{1240}$, annual rainfall, spring and spring-summer rainfall and September SPEI 6 and December SPEI 12 indices) correlated well with increases in aboveground biomass and with tree mortality rates. In contrast, other variables (GPP, PsnNet and summer rainfall) were not clearly correlated with increased biomass or tree mortality rates. Mean annual temperature was negatively correlated with increased biomass and positively correlated with tree mortality rates (Figs. 8 and 9).

\section{Discussion.}

245 The dry conditions increased stem mortality and decreased tree growth in the holm oak 246 forest (Barbeta et al. 2013; Ogaya and Peñuelas 2007). The constant increase in spring 
247 and summer temperatures during 1975-2012 led to higher vapor-pressure deficits, and

248 the September SPEI 3 and September SPEI 6 indices had negative values during the

249 most recent years, particularly in September 2011. The atmospheric moisture demand is

250 the primary mechanism by which high temperatures influence drought-sensitive tree

251 populations (Liu et al. 2013), and this is consistent with our negative relationship

252 between mean annual temperature and biomass increase and with our positive

253 relationship between mean annual temperature and tree mortality rates. As expected,

254 higher precipitation induced larger increases in biomass, with the exception of summer

255 rainfall. The negative relationship between summer rainfall and increased biomass must

256 be due to other climatic circumstances more conducive to tree growth, such as annual

257 rainfall or September SPEI indices, because summer rainfall was always low.

258 The mortality of autumn 2011 coincided with a heavy infestation of $C$.

259 nymphagoga during late spring 2011 that consumed a large proportion of recently

260 flushed leaves. After recent droughts in Catalonia, particularly in summer 1994 when

$26180 \%$ of $Q$. ilex individuals in some areas had lost all their foliage (Lloret and Siscart

262 1995), a high percentage of $Q$. ilex trees resprouted from the base of the trunk, the upper

263 branches of the canopy or both after the mortality induced by the extremely dry

264 conditions (Espelta et al. 1999). The percentage of resprouting $Q$. ilex trees after the

265 autumn 2011 mortality in our study forest, though, was negligible. The deterioration in

266 the condition of the crown in Q. ilex soon after autumn 2011 was clearly associated with

267 lower carbon reserves, and defoliated trees generally had less stored non-structural

268 carbohydrates than did healthy trees (Rosas et al. 2013). For these reasons, carbon

269 starvation induced by the continuous increase of temperatures during dry periods may

270 be a key factor of forest dieback at our study site. 
MODIS provides a large variety of remote sensing indices widely used in ecophysiological studies for determining plant activity and ecosystemic productivity 273 (Peñuelas and Filella 1998). In our holm oak forest, the correlation between the $274 \mathrm{R}_{858} / \mathrm{R}_{1240}$ ratio and biomass increase and the negative relationship with tree mortality 275 rates may be due to the importance of water availability in determining tree growth in 276 this Mediterranean ecosystem. Other indices such as LAI and FPAR were also 277 positively correlated with biomass increase and negatively correlated with tree mortality, 278 because FPAR depends on the total amount of leaves in the canopies. A decrease in the total amount of leaves remaining in the canopies of this forest was observed in $Q$. ilex 280 under simulated drought conditions (Ogaya and Peñuelas 2006). NDVI and EVI indices 281 were also well correlated with biomass increase, as has been observed in many other 282 works (Gamon et al. 1995). High correlations between stem growth and EVI values 283 have also been observed in this forest (Garbulsky et al. 2013). Despite their seasonal variability, the lowest NDVI and EVI values occurred in late autumn 2011 (when tree mortality occurred) and did not recover typical values until late spring 2012 (soon after

286 the flush of new leaves), showing again that NDVI and EVI indices are good indicators

287 of crown condition and forest dieback. In contrast, annual GPP, PsnNet and NPP values were poorly correlated with biomass increase or tree mortality rates, and seasonal GPP and PsnNet values did not significantly decrease during the period of tree mortality and

290 subsequent months. This result was unexpected because these algorithms are 291 specifically designed to directly estimate ecosystemic productivity.

292 In conclusion, the continuing increase of temperatures in this Mediterranean 293 ecosystem has been correlated with lower growth rates and higher forest dieback. Some 294 remote-sensing indices, such as NDVI and EVI, were good indices for estimating 295 annual productivity and for determining the occurrence of forest dieback, whereas other 
296 indices such as GPP, PsnNet and NPP were less useful for estimating productivity or for

297 detecting tree mortality, at least in the holm oak forest studied.

298

299

300 Acknowledgments.

301

302 We are grateful to DARP (Generalitat de Catalunya), X. Buqueras and A. Vallvey for

303 permission and assistance to conduct this research in the Poblet Holm Oak Forest.

304

305

306 Funding.

307 This research was financially supported by the Spanish Government projects

308 CGL2013-48074-P and Consolider-Ingenio MONTES CSD2008-00040, by the

309 Catalan government project SGR2014-274 and by the ERC Synergy project SyG-

310 2013-610028 IMBALANCE-P.

311

312

313

314

315

316

317

318

319

320 


\section{References.}

327 Allen CD, Macalady AK, Chenchouni H, Bachelet D, McDowell N, Vennetier M, 328 Kitzberger T, Rigling A, Breshears DD, Hogg EH, González P, Fensham R, Zhang Z,

329 Castro J, Demidova N, Lim JH, Allard G, Running SW, Semerci A, Cobb N (2010) A 330 global overview of drought and heat-induced tree mortality reveals emerging climate 331 change risks for forests. Forest Ecol Manag 259:660-684.

332

333 Barbeta A, Ogaya R, Peñuelas J (2013) Dampening effects of long-term experimental 334 drought on growth and mortality rates of a Holm oak forest. Global Change Biol In 335 press.

337 Bates BC, Kundzewicz ZW, Wu S, Palutikof JP (2008) Climate Change and Water. 338 Technical Paper of the Intergovernmental Panel on Climate Change. pp. 210.

340 Breshears DD, Cobb NS, Rich PM, Price KD, Allen CD, Balice RG, Romme WH,

341 Kastens JH, Floyd ML, Belnap J, Anderson JJ, Myers OB, Meyer CW (2005) Regional 342 vegetation die-off in response to global-change-type drought. Proc Natl Acad Sci USA 343 102:15144-15148. 
345 Breshears DD, Myers OB, Meyer CW, Barnes FJ, Zou CB, Allen CD, McDowell NG,

346 Pokman WT (2009) Tree die-off in response to global change-type drought: mortality

347 insights froma decade of plant water potential measurements. Front Ecol Environ 7:185348189.

349

350 Carnicer J, Coll M, Ninyerola M, Pons X, Sanchez G, Peñuelas J (2011) Widespread

351 crown condition decline, food web disruption, and amplified tree mortality with 352 increased climate change-type drought. Proc Natl Acad Sci USA 108: 1474-1478.

353

354 CREAF (2009) Land Cover Map of Catalonia (MCSC), 4th Edition. 355 http://www.creaf.uab.es/mcsc/usa/index.htm. Accessed 23 September 2009

356

357 Espelta JM, Sabaté S, Retana J (1999) Resprouting dynamics. In: Rodà F, Retana J, 358 Gracia C, Bellot J (eds) Ecology of Mediterranean evergreen oak forests. Springer, 359 Berlin, pp 61-73

360

361 Fischer EM, Schar C (2010) Consistent geographical patterns of changes in high-impact

362 European heatwaves. Nature Geosc 3:398-403

363

364 Galiano L, Martinez-Vilalta J, Sabate S, Lloret F (2012) Determinants of drought 365 effects on crown condition and their relationship with depletion of carbon reserves in a 366 Mediterranean holm oak forest. Tree Physiol 32:478-489. 
Gamon JA, Field CB, Goulden M, Griffin K, Hartley A, Joel G, Peñuelas J, Valentini, R

369 (1995) Relationships between NDVI, canopy structure, and photosynthetic activity in 370 three Californian vegetation types. Ecol Appl 5:28-41.

371

372 Garbulsky M, Peñuelas J, Ogaya R, Filella (2013) Leaf and stand-level carbon uptake of 373 a Mediterranean estimated using the satellite-derived reflectance indices EVI and PRI.

374 Int J Remote Sens 34:1282-1296.

375

376

Huete A, Didan K, Miura T, Rodriguez EP, Gao X, Ferreira LG (2002) Overview of the 377 radiometric and biophysical performance of the MODIS vegetation indices. Remote 378 Sens Environ 83:195-213.

379

380 IPCC (2013) Climate change 2013: The physical Science Basis. Contribution of 381 Working Group I to the Fifth Assessment Report of the Intergovernmental Panel on 382 Climate Change. In: Stocker TF, Qin D, Plattner GK, Tignor MMB, Allen SK, 383 Boschung J, Nauels A, Xia Y, Bex V, Midgley PM (eds) Cambridge University Press, 384 Cambridge, United Kingdom and New York, NY, USA. pp 986.

386 Lepš J, Šmilauer P (2003) Multivariate analysis of ecological data using CANOCO. 387 Cambridge Univ. Press, Cambridge.

389 Liu H, Williams AP, Allen CD, Guo D, Wu X, Anenkhonov OA, Liang E, Sandanov 390 DV, Yin Y, Qi Z, Badmaeva NK (2013) Rapid warming accelerates tree growth decline 391 in semi-arid forests of Inner Asia. Global Change Biol19: 2500-2510. 
393 Lloret F, Siscart D (1995) Demographic drought effects on holm oak populations. Cuad

394 Soc Esp Cien Forest 2:77-81.

395

396 Lloret F, Peñuelas J, Ogaya (2004) Establishment of co-existing Mediterranean tree 397 species under a varying soil moisture regime. J Veg Sci 15:237-244.

398

399 Mueller B, Seneviratne S (2012) Hot days induced by precipitation deficits at the global 400 scale. Proc Natl Acad Sci USA 109: 12398-12403.

401

402 Ogaya R, Peñuelas J (2003) Comparative seasonal gas exchange and chlorophyll 403 fluorescence of two dominant woody species in a Holm Oak forest. Flora 198: 132-141. 404

405

Ogaya R, Peñuelas J. 2004. Phenological patterns of Quercus ilex, Phyllirea latifolia, 406 and Arbutus unedo growing under a field experimental drought. Écoscience 11: 263-270. 407

408 Ogaya R, Peñuelas J (2006) Contrasting foliar responses to drought in Quercus ilex and 409 Phillyrea latifolia. Biol Plantarum 50: 373-382.

410

411 Ogaya R, Peñuelas J (2007) Tree growth, mortality, and above-ground biomass 412 accumulation in a holm oak forest under a five-year experimental field drought. Plant 413 Ecol 189: 291-299.

414

415 Peng C, Ma Z, Lei X (2011) A drought-induced pervasive increase in tree mortality 416 across Canada's boreal forests. Nature Clim Change. DOI: 10.1038/nclimate1293. 
418 Peñuelas J, Filella I, Llusià J, Siscart D, Piñol J (1998) Comparative field study of

419 spring and summer leaf gas Exchange and photobiology of the Mediterranean trees $420 \quad$ Quercus ilex and Phillyrea latifolia. J Exp Bot 49: 229-238.

421

422 Peñuelas J, Filella I (1998) Visible and near-infrared reflectance techniques for 423 diagnosing plant physiological status. Trends Plant Sci 3: 151-156.

Rosas T, Martínez-Vilalta J, Galiano L (2013) Non-structural carbohydrates in three Mediterranean woody species are unaffected by long-term experimental drought. Submitted.

Tucker CJ, Vanpraet CL, Sharman MJ, Vanittersum G (1985) Satellite Remote-Sensing 430 of Total Herbaceous Biomass Production in the Senegalese Sahel - 1980-1984. Remote Sens Environ 17: 233-249.

433 Vicente-Serrano SM, Begueria S, Lopez-Moreno JI (2010) A Multiscalar Drought 434 Index Sensitive to Global Warming: The Standardized Precipitation Evapotranspiration 435 Index. J Climate 23: 1696-1718.

436

437 Williams AP, Allen CD, Macalady AK, Griffin D, Woodhouse CA, Meko DM, 438 Swetnam TW, Rauscher SA, Seager R, Grissino-Mayer HD, Dean JS, Cook ER, 439 Gangodagamage C, Cai M, McDowell NG (2012) Temperature as a potent driver of 440 regional forest drought stress and tree mortality. Nature Clim Change. DOI: $441 \quad 10.1038 /$ nclimate1693. 
Tables.

444

445 Table 1. Coefficients of determination $\left(R^{2}\right)$ of the linear relationships of biomass 446 increase and mortality with spectral indices and meteorological variables. (N.S. means 447 not significant).

448

\begin{tabular}{|l|l|l|}
\hline & Biomass Increase & Mortality \\
\hline NDVI & 0.64 & 0.43 \\
\hline EVI & 0.55 & 0.35 \\
\hline GPP & N.S. & N.S. \\
\hline PsnNet & N.S. & N.S. \\
\hline
\end{tabular}

449

\begin{tabular}{|l|l|l|}
\hline Annual precipitation & 0.53 & 0.24 \\
\hline Spring precipitation & 0.44 & 0.31 \\
\hline Spring + Summmer & 0.41 & 0.34 \\
precipitation & & \\
\hline Mean annual temperature & N.S. & 0.33 \\
\hline Spring & 0.16 & 0.38 \\
temperature & & 0.31 \\
\hline September SPEI 6 & 0.30 & 0.27 \\
\hline December SPEI 12 & 0.45 & \\
\hline
\end{tabular}


$454 \quad$ Figure captions.

455

456 Figure 1. Study site with the land-cover types obtained from the "Land Cover Map of

457 Catalonia" (CREAF 2009) (modified legend). The study site is depicted by a red square

458 in the map of Europe. The 20 selected pixels of NDVI and EVI values are framed in

459 black. The other values were calculated in $1 \times 1 \mathrm{~km}$ pixel, centered in the middle of

460 these pixels, and covering the area of 16 depicted pixels.

461

462 Figure 2. Photographs showing the mortality in the studied forest during early autumn

4632011 and the same forest with healthy trees in autumn 2010.

464

465

Figure 3. Mean annual temperature and annual precipitation at the study site. The 466 straight lines represent the linear relationships of an increase of air temperatures and a decrease of rainfall during the 36 years that meteorological data were collected. N.S. means not significant. Each point indicates the mean value of 1 year.

469

470

Figure 4. Monthly data of air temperatures and precipitation during 2011 (black points) compared to the average data during 1975-2010 (white points and grey columns). Each point and column indicates the mean value of 1 month. Error bars indicate the standard errors of the means for 1975-2010.

474

475 Figure 5. Values of September standardized precipitation evapotranspiration index 476 (SPEI) for 1975-2012. SPEI 3 is calculated with meteorological data during the three 477 months before September (included), and SPEI 6 is calculated with data during the six 478 months before September (included). 
480 Figure 6. Monthly variations of the normalized difference vegetation index (NDVI) and 481 the enhanced vegetation index (EVI) in 2011 and 2012 (black points) compared to the 482 average of 2000-2010 (white points). Each point indicates the mean value of 1 month. 483 Error bars indicate the standard errors of the means for 2000-2010.

485 Figure 7. Monthly variations of gross primary production (GPP) and net photosynthesis 486 (PsnNet)in 2011 (black points) compared to the average of 2000-2010 (white points).

487 Error bars indicate the standard errors of the means for 2000-2010.

489 Figure 8. RDA biplot representing the relationships of the physical data on biomass 490 increase. Abbreviations: "temp" is mean annual temperature, "spring-summer" is the 491 sum of spring and summer rainfall and "SPEI 6" and "SPEI 12" are the September SPEI 6 and December SPEI 12 indices, respectively.

494 Figure 9. RDA biplot representing the relationships of the physical data on mortality. Abbreviations: "temp" is mean annual temperature, "spring-summer" is the sum of 496 spring and summer rainfall and "SPEI 6" and "SPEI 12" are the September SPEI 6 and December SPEI 12 indices, respectively. 


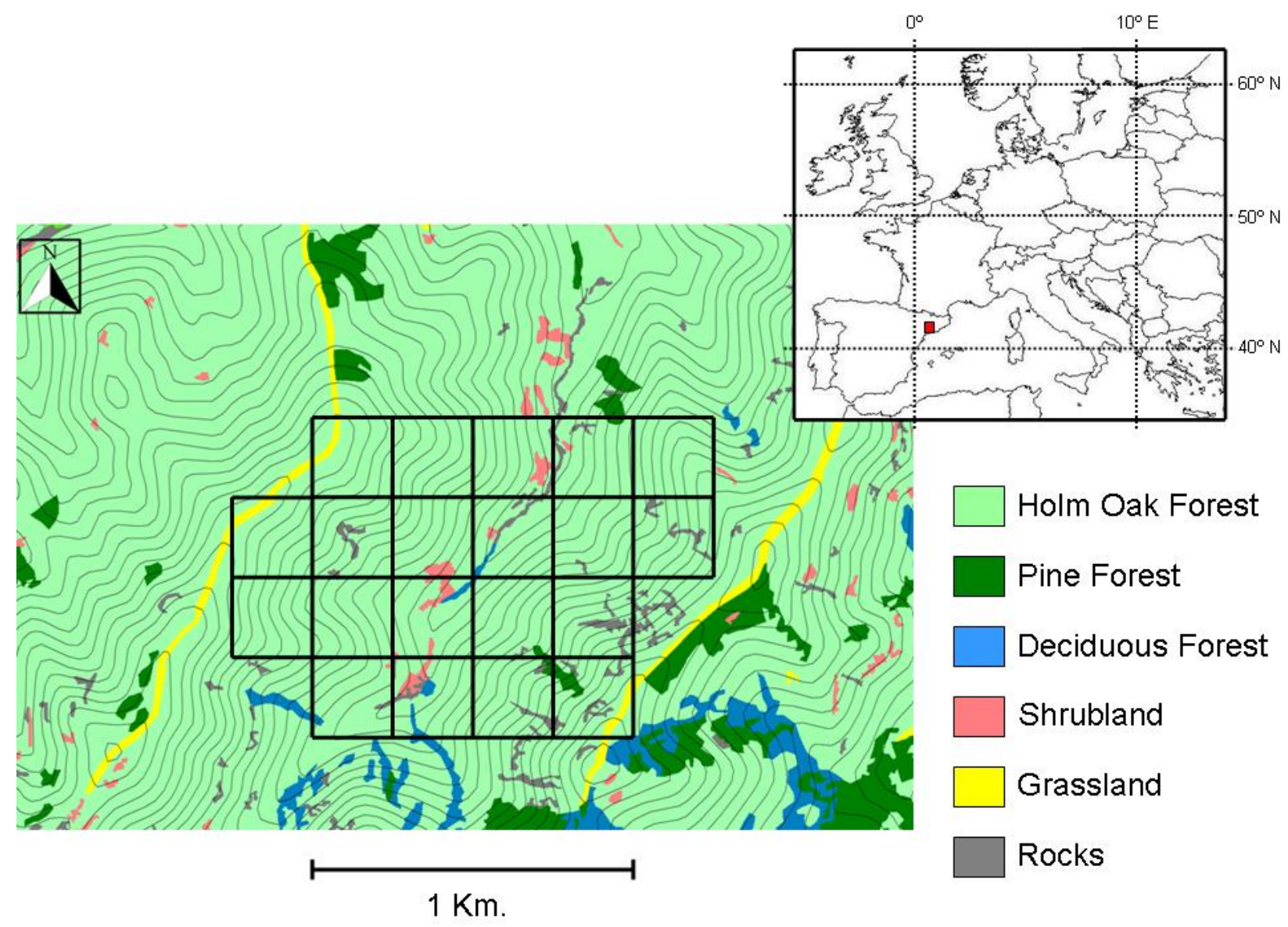

$510 \quad$ Fig. 1

511

512

513

514

515

516 
518

519

520

521

522

523

524

Autumn 2010

Autumn 2011

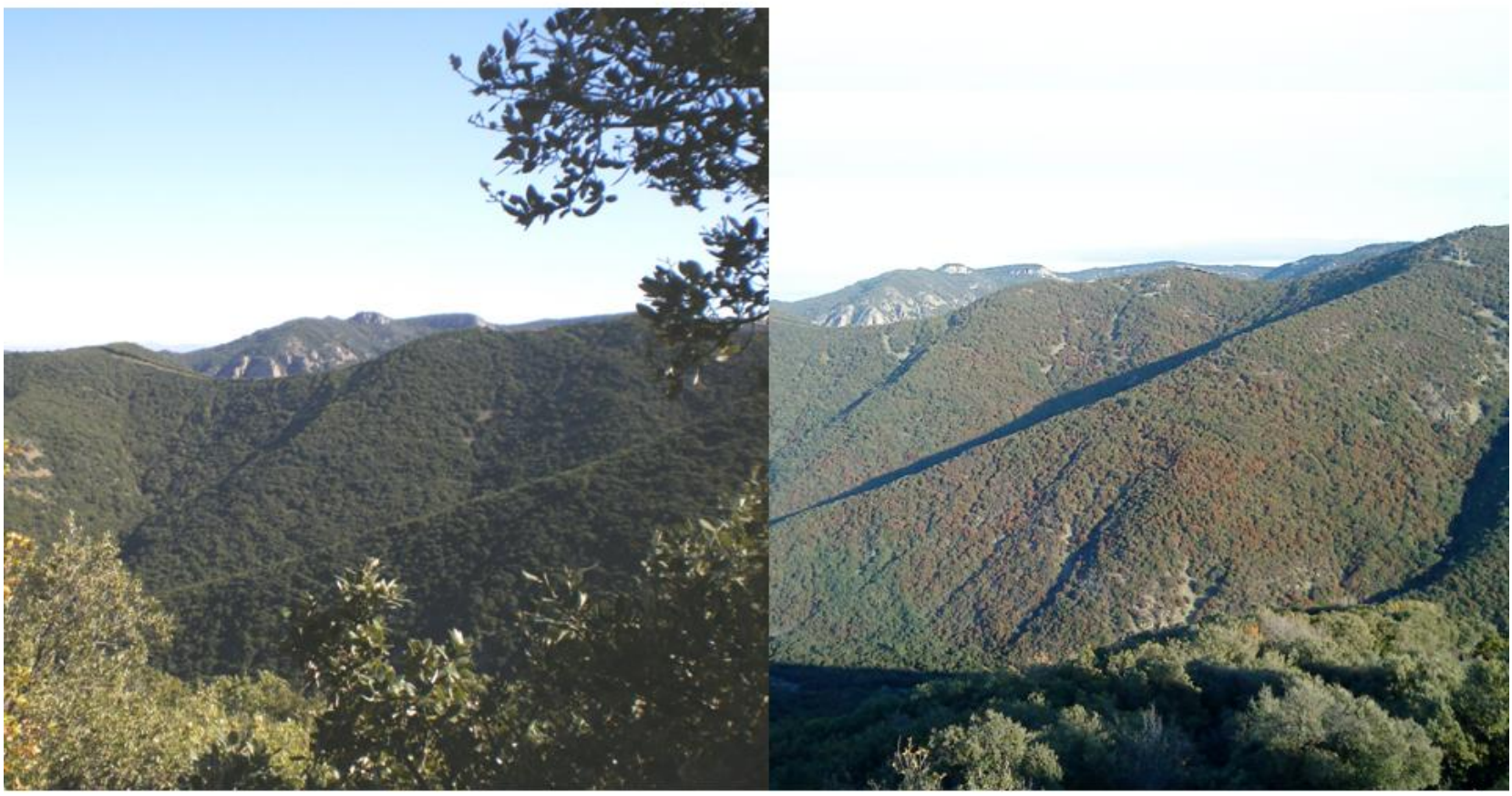

525

526 Fig. 2

527

528

529 


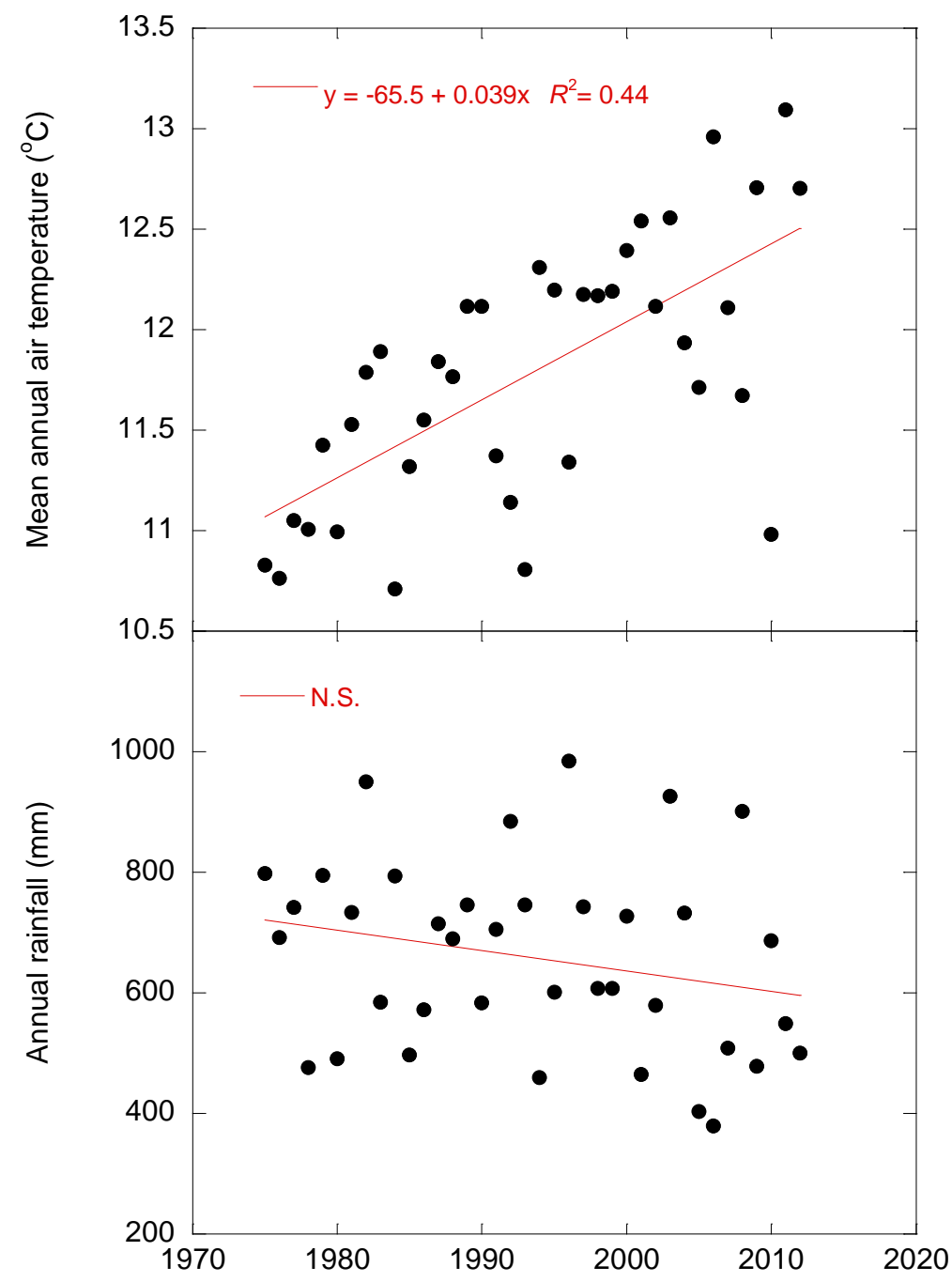

$535 \quad$ Fig. 3 
537

538

539

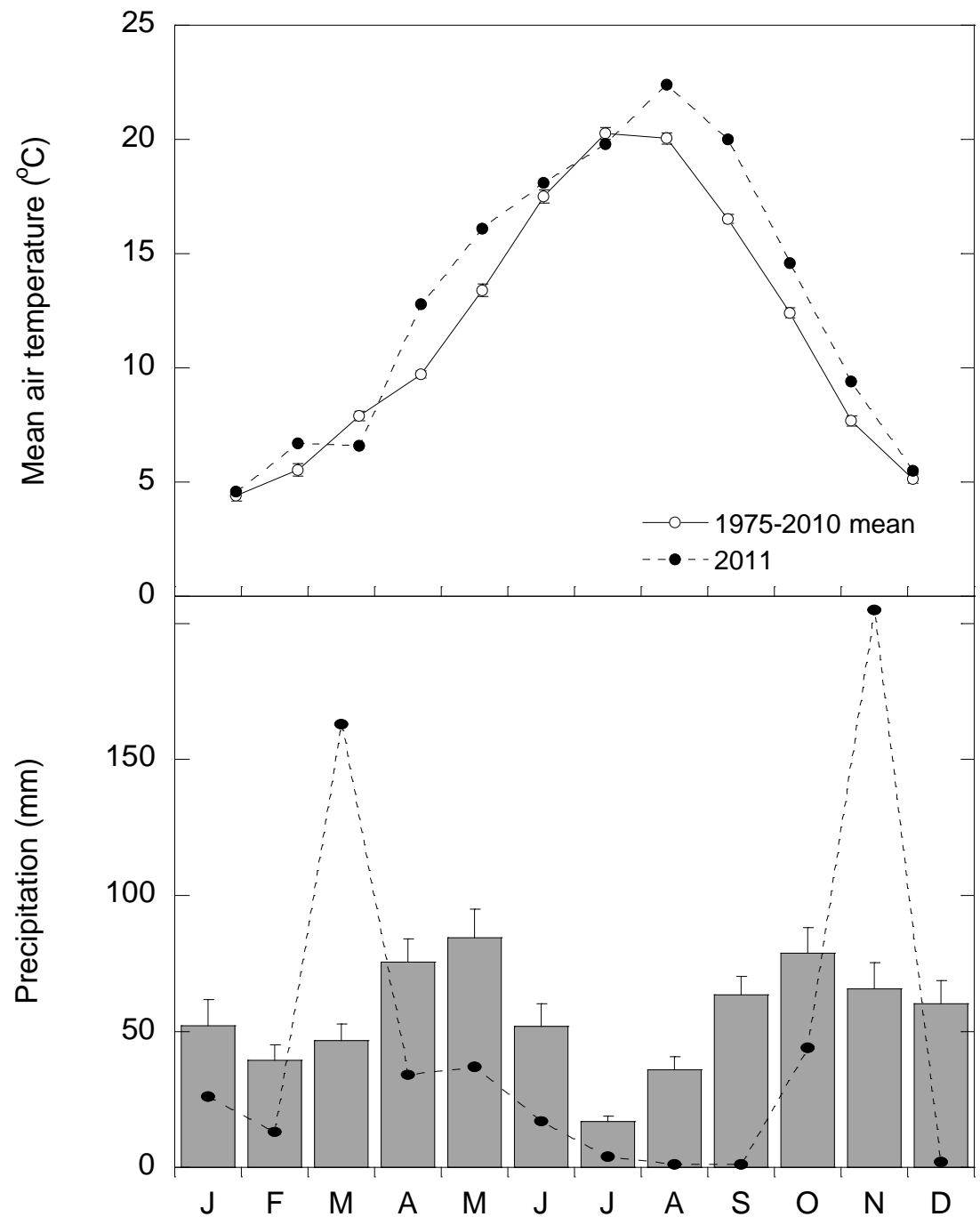

$541 \quad$ Fig. 4 


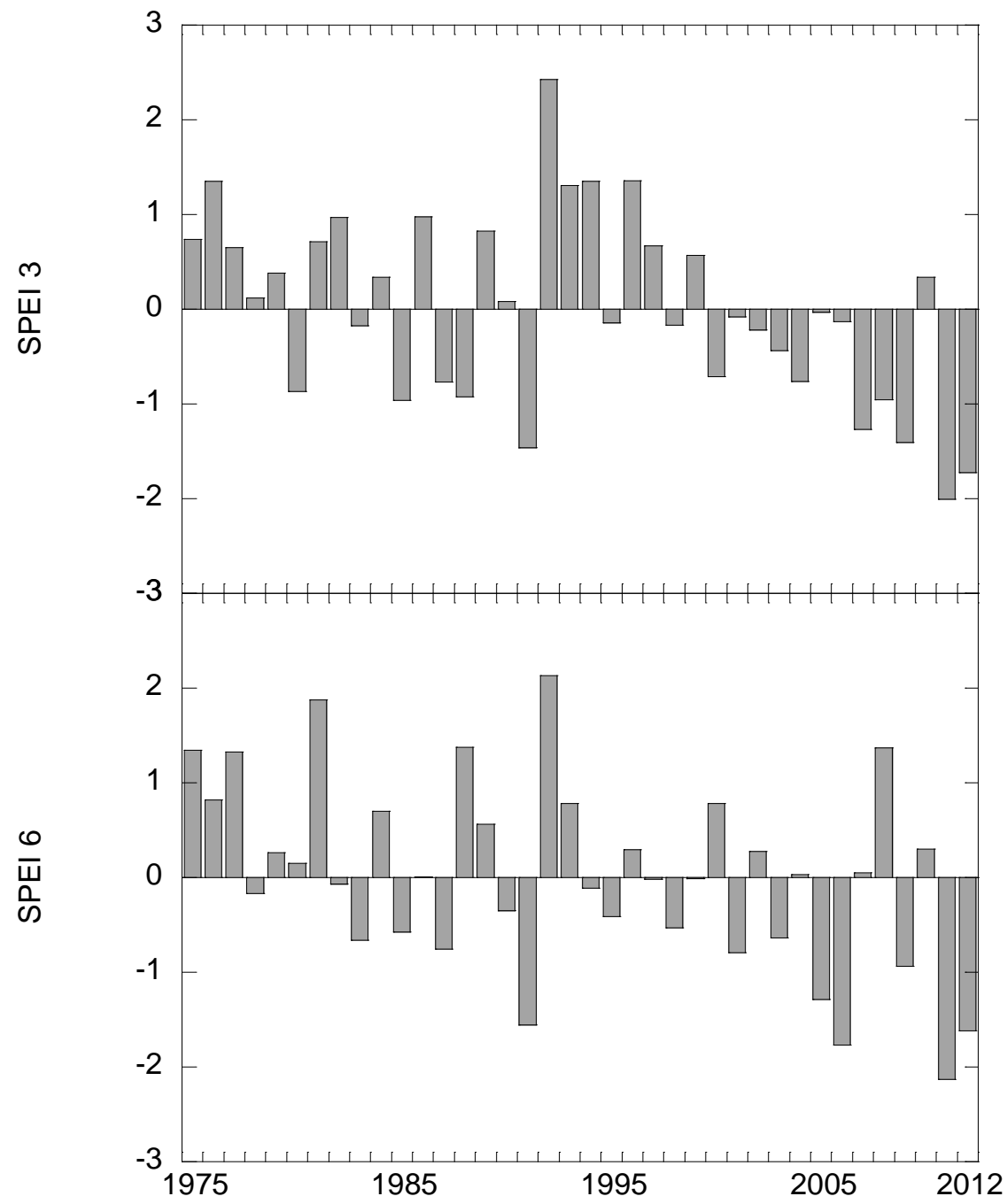

$547 \quad$ Fig. 5 


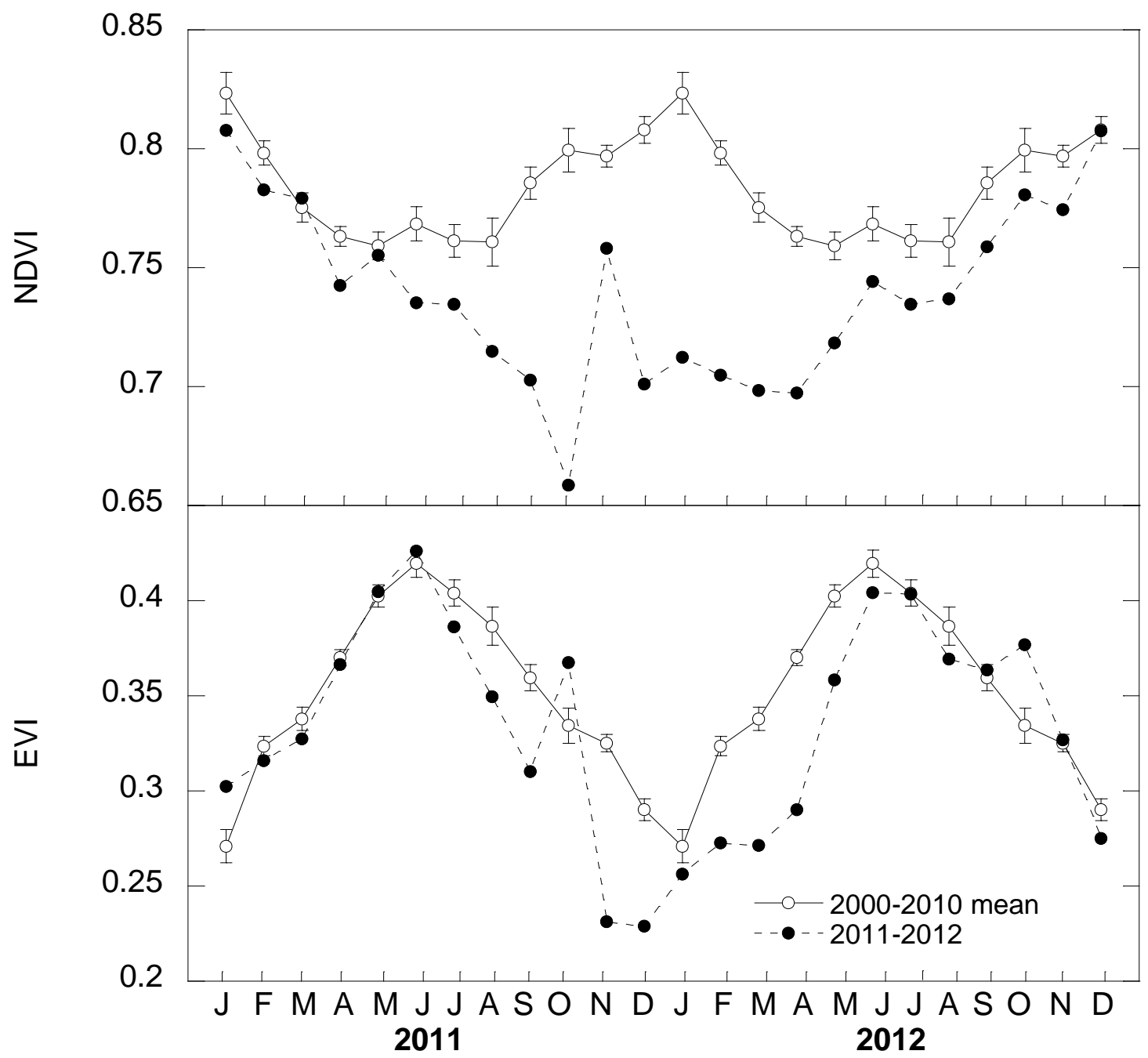

554

Fig. 6 
560

561

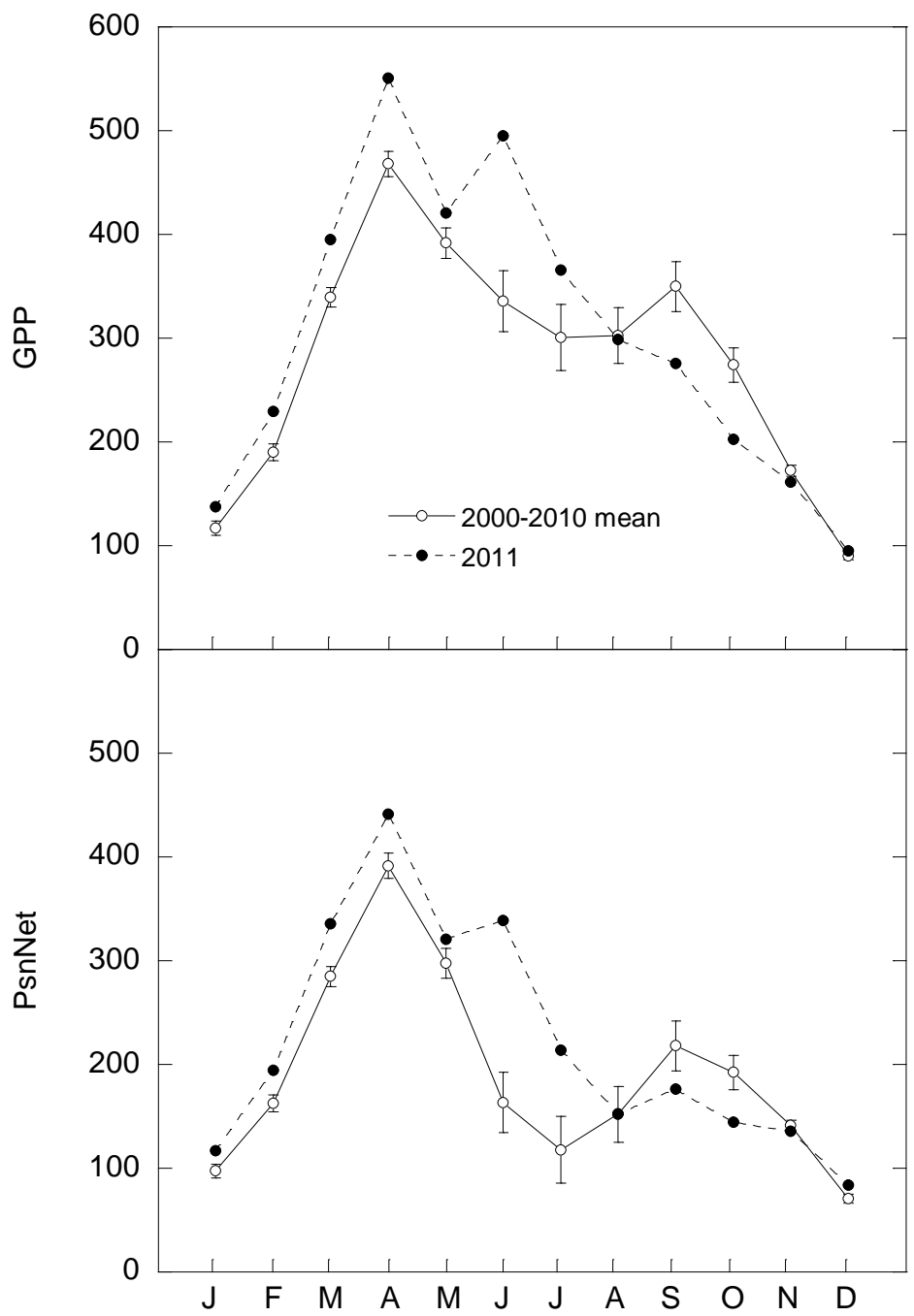

562

563

$564 \quad$ Fig. 7 
566

567

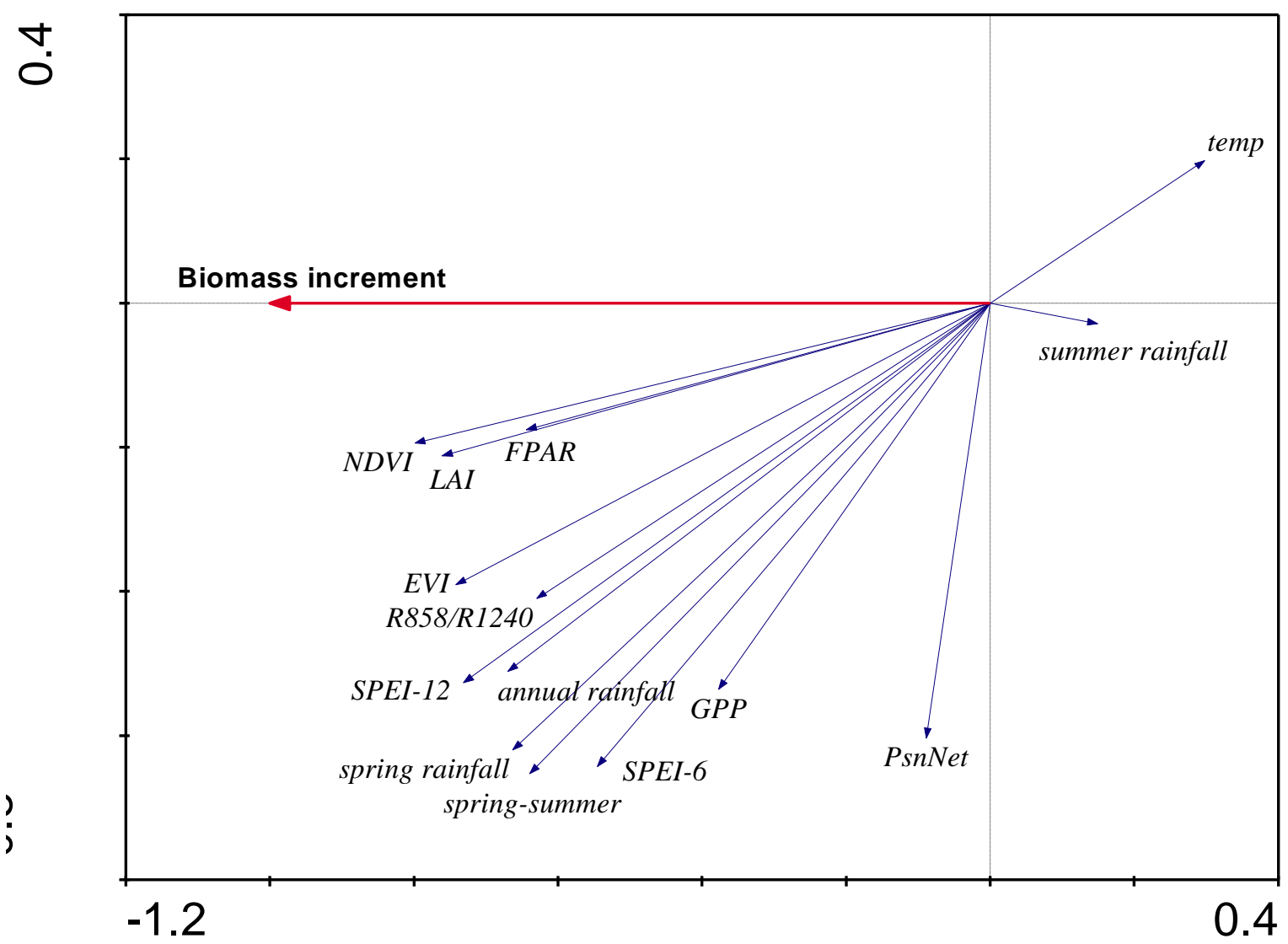

568

569

$570 \quad$ Fig. 8

571

572

573

574

575

576

577 
580

581

582

583

584

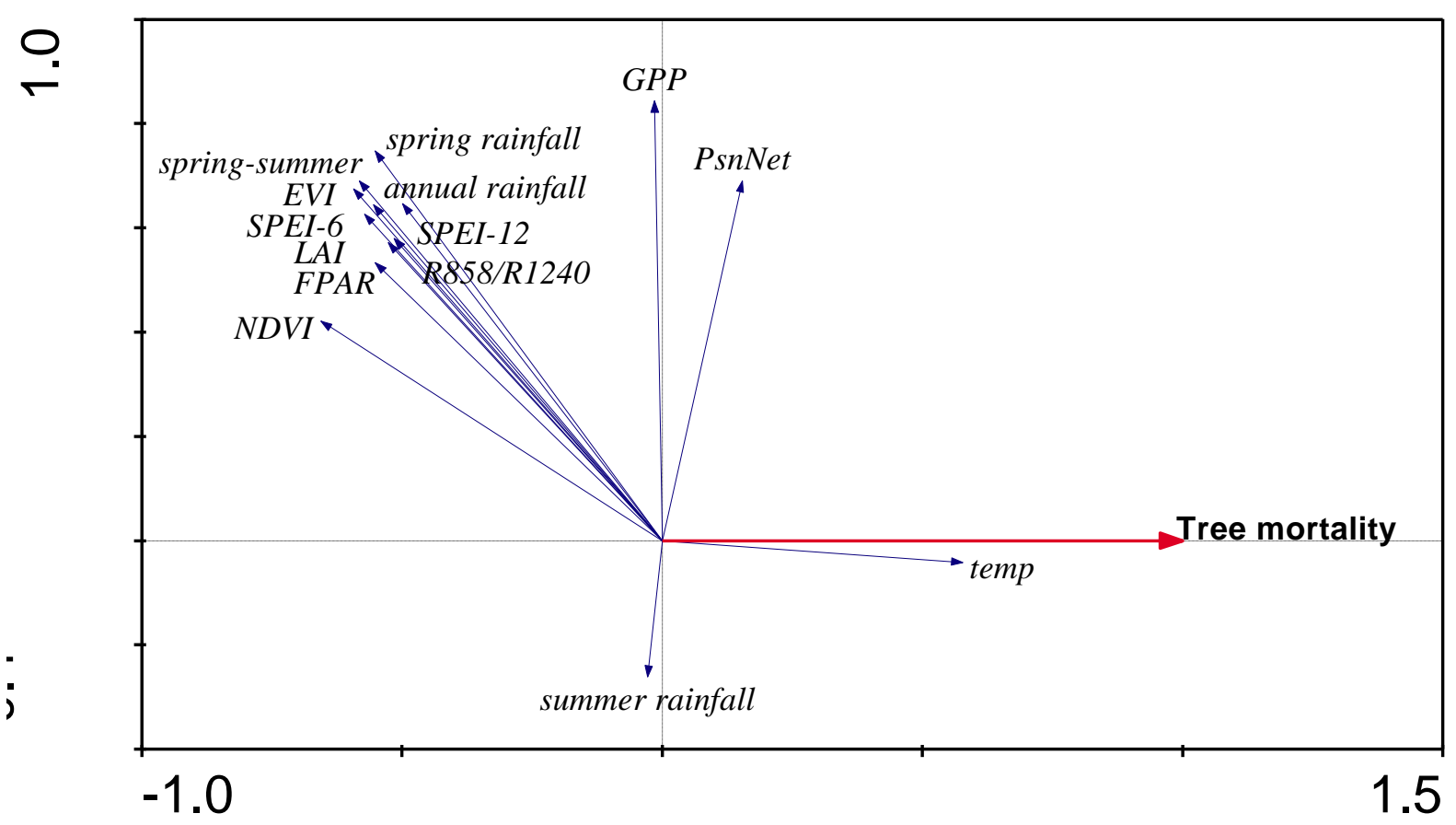

585

586

587 Fig. 9 